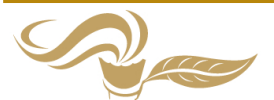

\title{
The Need for Transdisciplinarity in Higher Education in a Globalized World
}

\author{
Basarab Nicolescu, International Center for Transdisciplinary Research and Studies (CIRET), Paris, France and \\ University Babes-Bolyai, Cluj-Napoca, Romania, Email: nicol@club-internet.fr
}

doi: $10.22545 / 2012 / 00031$

\section{A} viable education can only be an integral education of the human being. Transdisciplinary education is founded on the inexhaustible richness of the scientific spirit which is based on questioning, and of the refusal of all a priori answers and all certitude contradictory to the facts. At the same time, it revalues the role of the deeply rooted intuition, of the imaginary, of sensitivity, and of the body in the transmission of knowledge. It is only in this way that the society of the twenty-first century can reconcile effectivity and respect for the potentiality of every human being. The transdisciplinary approach will be an indispensable complement to the disciplinary approach, because it will mean the emergence of continually connected beings, who are able to adapt themselves to the changing exigencies of professional life, and who are endowed with a permanent flexibility which is always oriented towards the actualization of their interior potentialities. If the University intends to be a valid actor in sustainable development it has first to recognize the emergence of a new type of knowledge: transdisciplinary knowledge. The new production of knowledge implies a necessary multidimensional opening of the process of learning: towards civil society; towards cyber-space-time; towards the aim of universality; towards a redefinition of the values governing its own existence.

Key Words: higher education, transdisciplinarity, levels of reality, logic of the included middle, nature, epistemology.

\section{Introduction}

Why transdisciplinarity is today not only realistic a realistic aim but also a necessary one?

The first argument is the big-bang of the number of disciplines who increased from 7 (when first universities were founded in the 13th century), to more than 8000 en 2012. A great expert in a given discipline is totally ignorant in more than 7999 disciplines. The decisions which are taken in our troubled world are based on ignorance and this fact provokes inevitable crisis which will be deeper and deeper in the future.

Second argument: the rapid changes in our contemporary world induce more and more unemployment and therefore human beings have to change their jobs several times during their active life. But passing from one job to another is practically impossible in the context of an accelerated superspecialization.

Third argument: recent discoveries in neurophysiology illustrated, for example, by the works of Antonio Damasio [1], underline the unexpected fact that the analytic intelligence is too slow compared with the intelligence of feelings. Therefore, we have 
Table 1: Comparison between disciplinary education (DE) and transdisciplinary education (TE).

\begin{tabular}{|l|l|}
\hline Disciplinary education (DE) & Transdisciplinary education (TE) \\
\hline IN VITRO & IN VIVO \\
\hline \hline One level of Reality & Several levels of Realitys \\
\hline External world - Object & $\begin{array}{l}\text { Correspondence between external world (Object) } \\
\text { and internal world (Subject) }\end{array}$ \\
\hline Accumulation of knowledge & Understanding \\
\hline Analytic intelligence & $\begin{array}{l}\text { New type of intelligence - harmony } \\
\text { between mind, feelings and body }\end{array}$ \\
\hline $\begin{array}{l}\text { Binary logic } \\
\text { (absolute truth / absolute falseness) }\end{array}$ & $\begin{array}{l}\text { Included middle logic } \\
\text { (relative truth) }\end{array}$ \\
\hline $\begin{array}{l}\text { Oriented towards } \\
\text { power and possession }\end{array}$ & $\begin{array}{l}\text { Oriented towards } \\
\text { astonishment and sharing }\end{array}$ \\
\hline Exclusion of values & Inclusion of values \\
\hline
\end{tabular}

to find equilibrium in our educative system between the analytic intelligence and the interior being.

Fourth argument: globalization induces an enormous migratory flux of people belonging to countries of a given culture, religion and spirituality towards countries of another culture, religion and spirituality. The new education has to establish the dialogue between cultures, religions and spiritualities.

Fifth argument: the rapid advance of means of communication implies an increased complexity in an interconnected world. The new education has to invent new methods of teaching, founded on new logics. The old classical binary logic, that of "yes" and "no", i. e. the logic of the excluded middle, is no more valid in the context of complexity.

The last argument I would like to formulate is the following: solving problems in the real world forces university to interact with society, industry, banks and ecology. These problems clearly belong to the field of "trans": their resolution asks us to go beyond academic disciplines. Transdisciplinarity is therefore realistic and necessary for the survival of universities.

\section{Disciplinary Education and Transdisciplinary Education}

The transdisciplinary knowledge corresponds to an in vivo knowledge, concerned with the correspondence between the external world of the Object and the internal world of the Subject. By definition, the transdisciplinary knowledge includes a system of values, the humanistic values. It leads to a new type of education-the transdisciplinary education (TE), distinct from but complementary to our present disciplinary education (DE) (see Table 1).

It is important to realize that the disciplinary knowledge and the transdisciplinary knowledge are not antagonist but complementary. Both their methodologies are founded on scientific attitude. Building the transdisciplinary mind at the University is our main challenge today.

In order to explore the new, transdisciplinary education, we have to apply the transdisciplinary methodology [2].

The methodology of transdisciplinarity is founded on three postulates:

1. The ontological postulate: There are, in Nature and in our knowledge of Nature, different levels of Reality of the Object and different levels of Reality of the Subject.

2. The logical postulate: The passage from one level of Reality to another is insured by the logic of the included middle.

3. The epistemological postulate: The structure of the totality of levels of Reality is a complex structure: every level is what it is because all the levels exist at the same time.

The first two postulates received, in the $20^{t h}$ century, experimental evidence from quantum physics [3], while the last one has its source not only in quantum physics but also in a variety of other exact and human sciences.

The key concept of the transdisciplinary approach to Nature and knowledge is the concept of levels of Reality [4]. 


\section{Emergence of a Transdisciplinary 5 Learning to Know Culture}

The emergence of a transdisciplinary culture capable of contributing to the elimination of the tensions menacing life on our planet will be impossible without a new type of education which takes into account all the dimensions of the human being.

All the various tensions-economic, cultural, spiritual-are inevitably perpetuated and deepened by a system of education founded on the values of another century, and by a rapidly accelerating imbalance between contemporary social structures and the changes which are currently taking place in the contemporary world. More or less embryonic wars between economies, cultures, and civilizations never stop leading, here and there, to actual wars. In fact, our entire individual and social life is structured by education. Education is at the center of our becoming. The future is shaped by the education which is delivered in the present, here and now.

In spite of the enormous diversity of the systems of education that can be found in various countries, the globalization of the challenges of our era involves the globalization of the problems of education. The different upheavals continually confronting education in one or another country are only symptoms of one and the same flaw: the disharmony which exists between the values and the realities of a planetary life in the process of change. Most certainly, while there is no miraculous recipe, there is nevertheless a common center of questioning which it would behoove us not to avoid if we truly want to live in a more harmonious world.

\section{The Delors Report}

Growing awareness of a system of education that does not keep pace with the modern world is demonstrated by numerous recent conferences, reports, and studies. The latest and most exhaustive report was developed by the International Commission on Education for the Twenty-First Century chaired by Jacques Delors, in cooperation with UNESCO [5]. The Delors Report strongly emphasized four pillars of a new kind of education: learning to know, learning to do, learning to live together, and learning to be. In this context, the transdisciplinary approach can make an important contribution to the advent of this new type of education.

Learning to know means first of all training in the methods which help us distinguish what is real from what is illusory, and in the techniques which enable intelligent access to the fabulous knowledge of our age. In this context the scientific spirit, one of the highest goals ever attained in the human adventure, is indispensible. Precocious initiation into science is beneficial because it provides access, from the very beginning of human life, to the inexhaustible richness of the scientific spirit which is based on questioning, and on the refusal of all a priori answers and all certitude contradictory to the facts. However, "the scientific spirit" does not at all mean the thoughtless increase of teaching scientific matters or retreating to an interior world based on abstraction and formalization. Although such excess is, unfortunately, still current, it can lead only to the exact opposite of the scientific spirit: previous ready-made answers are replaced by other new ready-made answers (this time, having a kind of "scientific" brilliance); thus, in the final analysis, one dogmatism is replaced by another. Nor is it the assimilation of an enormous quantity of scientific knowledge which gives access to the scientific spirit, but the quality of that what is taught. And here "quality" means to lead the child, the adolescent, or the adult into the very heart of the scientific approach, which is the permanent questioning related to the resistance of facts, images, representations, and formalizations.

Learning to know also means being capable of establishing bridges-between the different disciplines, and between these disciplines and meanings and our interior capacities. This transdisciplinary approach will be an indispensable complement to the disciplinary approach, because it will mean the emergence of continually connected beings who are able to adapt themselves to the changing exigencies of professional life, and who are endowed with a permanent flexibility which is always oriented toward the actualization of their interior abilities.

\section{Learning to Do}

Learning to do certainly means acquiring a profession or a craft and theoretical and practical knowledge which is associated with it. The acquisition of a profession or craft necessarily passes through a phase of specialization. One cannot do open-heart surgery if one has not learned surgery; one cannot solve a 
third-degree equation if one has not learned mathematics; one cannot be a producer without knowing theatrical techniques.

However, in our tumultuous world, in which the tremendous changes induced by the information revolution are but the portent of other still more tremendous changes to come, any life which is frozen into one and the same occupation can be dangerous, because it risks leading to unemployment, to exclusion, to a debilitating alienation. Excessive, precocious specialization should be outlawed in a world which is in rapid change. If one truly wants to reconcile the exigency of competition with the imperative of equal opportunity for all human beings, in the future every profession and every craft should be an authentically woven occupation, an occupation which would bind together in the interior of human beings threads joining them to other occupations. Of course, it is not simply a question of acquiring several competencies at the same time but of creating a flexible, interior core which could quickly provide access to another occupation, should that become necessary or desirable.

Here also, the transdisciplinary approach can be invaluable. In the last analysis, "learning to do" is an apprenticeship in creativity. "To make" also signifies discovering novelty, creating, bringing to light our creative potentialities. It is this aspect of "making" which is contrary to the boredom and sometimes even despair which is experienced by so many human beings who are obliged to exercise an occupation which does not conform to their interior predispositions simply in order to underwrite their basic needs. "Equal opportunity" also means the opportunity for the actualization of the creative potentialities which vary from one person to the next. Competition could also mean the harmony of creative activities within a single community. Boredom and despair, the source of violence, conflict, and of moral and social resignation can be replaced by the joy of personal realization, no matter what the place where this realization is effected, because a place can only be unique for each person at a given moment.

Creating the conditions for the emergence of authentic persons also means insuring the conditions for the maximal actualization of their creative potentialities. The social hierarchy, so frequently arbitrary and artificial, could thus be replaced by the cooperation of levels structured in order to serve personal creativity. Rather than being levels imposed by a competition which does not take the interior being into account at all, these levels would in fact be levels of being. The transdisciplinarity approach is based on the equilibrium between the exterior person and the interior person. Without this equilibrium, "to make" means nothing other than "to submit."

\section{Learning to Live Together}

Of course, learning to live together first of all signifies respect for the norms which govern relationships between the beings comprising a collective. However, these norms must be truly understood and willingly internalized by each being, rather than obeyed out of submission to exterior constraints. "To live together" does not mean simply tolerating others' differences of opinion, skin color, and beliefs; submission to the exigencies of power; negotiating between the in's and out's of innumerable conflicts; definitively separating interior from exterior life; and merely appearing to hear the other while remaining convinced of the absolute rightness of our own position. If this is what it means, "living together" is inevitably transformed into its opposite: fighting each other. The transcultural, transreligious, transpolitical, and transnational attitude can be learned. To some extent, in each being there is a sacred, intangible core that is innate. Yet, if this innate attitude remains merely a potential, it can forever stay non-actualized, absent in life and in action. In order for the norms of a collective to be respected, they must be validated by the interior experience of each being.

There is one fundamental characteristic of the transdisciplinary evolution of education: to recognize oneself in the face of the Other. This is a question of permanent apprenticeship, which must begin in early childhood and continue throughout life. The transcultural, transreligious, transpolitical, and transnational attitude permits us to better understand our own culture, to better defend our national interests, to better respect our own religious or political convictions. Just as in all other areas of Nature and knowledge, open unity and complex plurality are not antagonists.

\section{Learning to $\mathrm{Be}$}

Learning to be appears at first like an insoluble enigma. We know how to exist, but how can we learn to be? We can begin by learning what the word "exist" means, for us: discovering our conditioning, discovering the harmony or disharmony between our 
individual and social lives, testing the foundations of our convictions in order to discover that which is found underneath. In a building, the stage of excavation precedes that of foundation. In order to make a foundation for being, one must first of all proceed with the excavation of our certitudes, our beliefs, and our conditioning. To question, to question always; here also, the scientific spirit is a precious gift for us. This must be learned by the teachers as well as the taught. "Learning to be" is also a permanent apprenticeship, in which teachers inform students as students inform teachers. The shaping of a person inevitably passes through a transpersonal dimension. The disrespect for this necessary process helps explain one of the fundamental tensions of our era, that between the material and the spiritual. The survival of our species largely depends on the elimination of this tension by means of reconciliation between these two apparently antagonistic contradictions which takes place on another level of experience than that of everyday life. "Learning to be" also means learning to know and to respect that which joins the Subject and Object. The other remains an object for me if I do not make this apprenticeship, which teaches me that together we, the Other and me, create the Subject joined with the Object.

\section{The Integral Education of the Human Being}

There is one very obvious interrelationship between the four pillars of the new system of education: how to learn to make while learning to know, and how to learn to be while learning to live together?

In the transdisciplinary vision, there is also a transrelation which connects the four pillars of the new system of education and which has its source in our own constitution as human beings. This transrelation is like the roof which rests on four pillars of a building. If any one of the pillars of the building collapses, the entire building collapses, the roof with it. And, it there is no roof, the building falls into ruin.

A viable education can only be an integral education of the human being, according to the apt formulation of the poet Ren Daumal [6]: an education which is addressed to the open totality of the human being, not to just one of the components.

At present, education privileges the intellect over the emotions or the body. This was certainly necessary in the previous era, in order to permit the explosion of knowledge. But this privileging, if it continues, sweeps us away in the mad logic of efficacy for efficacy's sake, which can only lead to our self-destruction.

Of course it is not a question of limiting or increasing the number of hours provided for artistic or athletic activities. This would be like trying to obtain a living tree by juxtaposing roots, trunk, branches, and leaves. This juxtaposition would only lead to a semblance of a living tree. Contemporary education concerns itself with only the leaves. But leaves do not make a whole tree.

\section{The Experiments of Leon Lederman}

Experiments made by the Nobel Prize-winning physicist Leon Lederman with children from disadvantaged neighborhoods of Chicago demonstrates what we have been saying [7]. Lederman convinced some secondary school teachers to initiate new methods for teaching physics based on the touching of different objects and the discussion of contributions of different sense organs-sight, touch, smell - in the process. All this was play: it took place in an environment far removed from the usual formal apprenticeship in mathematics and physics. And the miracle happened. Even children who came from very poor families, where violence, lack of culture, and disinterest in the typical activities of children reigned supreme, discovered the abstract laws of physics through play. One year earlier, these same children had been declared incapable of ever understanding any abstraction. It is interesting, moreover, to point out that the greatest difficulties of the operation and - it goes without saying - the major part of its cost, were due to the resistance of the teachers: they had a great deal of trouble abandoning their old methods. The teaching of teachers proved longer and more difficult than the work with children.

The Chicago experiment shows well that the intelligence assimilates knowledge much better and much more rapidly when this knowledge is also understood with body and the emotions. In a living tree, the roots, the trunk, the branches and the leaves are inseparable: the sap which insures the life of the tree moves vertically through all of them. This is the prototype of what was previously referred to as the "revolution of intelligence": the emergence of a new type of intelligence, founded on the equilibrium between analytic intelligence, feelings, and the body. It 
is only in this way that the society of the twenty-first century can reconcile effectivity and affectivity.

\section{The Transdisciplinary Education as a Long-Term Process}

Transdisciplinarity education clarifies in a new way a need which is presently felt more and more - the need for a permanent education. In fact, transdisciplinary education, by its very nature, should take place not only in teaching institutions, from the kindergarten to the university, but also in the work place - in fact, everywhere, and throughout our life.

In teaching institutions there is no need to create new departments and new chairs; this would be contrary to the transdisciplinary spirit. Transdisciplinarity is not a new discipline, and a transdisciplinary researcher is not some new kind of specialist. The solution would be to create workshops for transdisciplinary research within every teaching institution. These workshops would be the locus for gathering together a group of teachers and students from a particular institution who generate and oversee their own organization and are all animated by the transdisciplinary attitude. The same experiment could be carried out within various enterprises, and within other collectives, as well as within national and international institutions.

There is one particular problem which is posed by transdisciplinary education outside professional life. In a balanced society, the boundary between leisure time and apprenticeship time would gradually disappear. The information revolution could play a considerable role in our life for transforming training into pleasure and pleasure into training. The problem of unemployment of the young would certainly be alleviated by a hitherto unsuspected solution. In this context, grassroots efforts will play an important role in transdisciplinary education throughout life.

It is quite obvious that the various areas and ages of life call for extremely diverse transdisciplinary methods. Even if transdisciplinary education is a long-term, global process, it is still important to discover and to create places which help to initiate this process and insure its development.

The university is the privileged place for an education geared toward the exigencies of our time which could also be the pivotal place for an education directed not only toward children and adolescents, but also toward adults.

\section{Peace and} Transdisciplinarity-The
Transcultural, Transreligious,
Transpolitical, and
Transnational Attitude

In the transdisciplinary perspective, there is a direct and unavoidable relation between peace and transdisciplinarity. Severely fragmented thought is incompatible with the research of peace on this Earth. The emergence of a culture and an education of peace require the transdisciplinary evolution of education and, especially, the transdisciplinary evolution of the university.

Instilling complex and transdisciplinary thought into the structures and programs of the university will permit its evolution toward its somewhat forgotten mission today-the study of the universal. The university could become a place of apprenticeship in the transcultural, transreligious, transpolitical, and transnational attitude, and in the dialogue between art and science which is the axis of a reunification between scientific culture and artistic culture. A renewed university would become the place for welcoming a new kind of humanism.

There is no need to invent a totally new University, but one needs to transform the existing disciplinary universities by adopting the transdisciplinary methodology as their complementary methodology.

\section{Conclusions}

Important steps in this direction were made in several countries [8]. In particular, $\mathrm{PhD}$ programs in transdisciplinarity are established now at the University Babes-Bolyai, Cluj-Napoca (Romania), Texas Tech University (USA) and at the University of Stellenbosch (South Africa) [9].

The transdisciplinary approach is realistic and even necessary for the survival of contemporary universities, placed in the chaotic context of globalization. One necessary condition is to understand what Reality is today. We are part of the ordered movement of Reality. Our freedom consists in entering into the movement or perturbing it. Reality depends on us. Reality is plastic. We can respond to the movement or impose our will of power and domination. Our responsibility is to build sustainable futures in agreement with the overall movement of reality. 
The emergence of a new culture capable of contributing to the elimination of the tensions menacing life on our planet will be impossible without a new type of learning which takes into account all the dimensions of the human being.

A viable education can only be an integral education of the human being. It is founded on a new type of intelligence, requiring the harmony between mind, feelings and body. The recent findings of neurophysiology show clearly the exceptional role of feelings in education.

Transdisciplinary education is founded on the inexhaustible richness of the scientific spirit which is based on questioning, and of the refusal of all a priori answers and all certitude contradictory to the facts. At the same time, it revalues the role of the deeply rooted intuition, of the imaginary, of sensitivity, and of the body in the transmission of knowledge. It is only in this way that the society of the twenty-first century can reconcile effectiveness and respect for the potentiality of every human being. The transdisciplinary approach will be an indispensable complement to the disciplinary approach, because it will mean the emergence of continually connected beings, who are able to adapt themselves to the changing exigencies of professional life, and who are endowed with a permanent flexibility which is always oriented towards the actualization of their interior potentialities.

Universal sharing of knowledge - a necessity of our world - cannot take place without the emergence of a new tolerance founded on the transdisciplinary attitude, one which implies putting into practice the transcultural vision. The transcultural attitude permits us to better understand our own culture, to better defend our national interests, to better respect our own religious or political convictions.

If the University intends to be a valid actor in sustainable development it has first to recognize the emergence of a new type of knowledge: transdisciplinary knowledge. The new production of knowledge implies a necessary multidimensional opening of the process of learning: towards civil society; towards cyber-space-time; towards the aim of universality; towards a redefinition of the values governing its own existence.

\section{References}

[1] Damasio A. R., 2003. Looking for Spinoza: Joy, Sorrow, and the Feeling Brain. San Diego: Harcourt.
[2] Nicolescu B., 2002. Manifesto of Transdisciplinarity. New York: State University of New York (SUNY) Press. Translation in English by Karen-Claire Voss.

[3] Nicolescu B., 2012. We, the Particle and the World / Nous, la particule et le monde. Brussels: E. M. E. $\S$ InterCommunications.

[4] Nicolescu, B., 2009. What is Reality? / Qu'est-ce que la Réalité? Montréal: Liber.

[5] Delors J., 1996. Learning: The Treasure Within. Report to UNESCO of the International Commission on Education for the Twenty-first Century. Paris: UNESCO Publishing.

[6] Daumal R., 1972. Essais et Notes, I, p. 276. Paris: Gallimard.

[7] Project ARISE - American Renaissance in Science Education. http://ed.fnal.gov/arise/index.html, accessed: October 30, 2012.

[8] Experiences of Transdisciplinary Education, 2005. Transdisciplinary Encounters, 18. Paris: CIRET. http:basarab.nicolescu.perso.sfr.fr/ciret/bulletin/b18. php, accessed: October 30, 2012.

[9] Transdisciplinary Doctoral Programs in the World. Paris: CIRET. http:basarab. nicolescu.perso.sfr.fr /ciret/doctorat.php, accessed: October 30, 2012.

\section{About the Author}

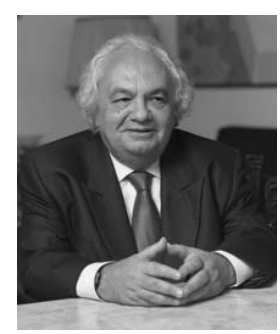

Basarab Nicolescu is a theoretical physicist in elementary particle physics at CNRS, France and professor of philosophy at the Babes-Bolyai University, Cluj-Napoca, Romania. He is member of the Romanian Academy and president-founder of the International Center for Transdisciplinary Research and Studies (CIRET). Basarab Nicolescu is founder and director of the Transdisciplinarity series, Rocher, Monaco, of the Romanians in Paris series, Oxus, Paris and of the Science and Religion and Science, Spirituality, Society Series, Curtea Veche, Bucharest. His books include: Manifesto of Transdisciplinarity, State University of New York (SUNY) Press, New York, 2002; Nous, la particule et le monde, E. M. E. § InterCommunications, Brussels, 2012 (3rd edition); Science, Meaning and Evolution - The Cosmology of Jacob Boehme, 
Parabola Books, New York, 1991. He edited Transdisciplinarity - Theory and Practice, Hampton Press, Cresskill, New Jersey, 2008. Forthcoming: Science, Culture and Spirituality - From Modernity to Cosmodernity, State University of New York (SUNY) Press, New York (to be published). A complete bio-bibliography of Basarab Nicolescu can be found on the page http://www.basarab-nicolescu.fr/index.php

Copyright (c) 2012 by the author. This is an open access article distributed under the Creative Commons Attribution License (https://creativecommons.org/licenses/by/4.0/), which permits unrestricted use, distribution, and reproduction in any medium, provided the original work is properly cited. 